\title{
PROGRESSIVE OSSIFYING FIBRODYSPLASIA: CASE REPORT
}

Fabiana Romani ${ }^{1}$, Simone de Menezes Karam ${ }^{2}$

\section{ABSTRACT}

Progressive ossifying fibrodysplasia is a rare genetic disease that affects one individual in every two million births. Its main consequence is heterotopic ossification, i.e. formation of additional bone in abnormal locations. It is an autosomal dominant disease, usually caused by a new mutation in the ACVR1 receptor gene, which is in the signaling pathway for bone morphogenic protein. This abnormality is not related to

\section{INTRODUCTION}

Individuals suffering from FOP can be recognized as people who form two skeletons: one in the normal place, which develops during the embryo formation phase; and another at an abnormal site, which develops after birth ${ }^{(1)}$. At birth, the child's skeleton is apparently normal; however, it already usually exhibits the first signs of the disease, which are varied skeletal malformations, the main one being malformation of the halluces ${ }^{(2)}$. This characteristic is present in $95 \%$ of patients with FOP. It is also possible to find other skeletal malformations such as defects in the cervical spine, short thumbs and osteochondromas in the proximal part of the tibia.

The disease usually starts in the neck and shoulders and progresses to the back, trunk and limbs.

The symptoms start to appear before the age of 20 years, and frequently before the age of 10 . They are characterized by reddish swellings in the shoulders and back that disappear with time, but that leave a bone in the place where there was inflammation. The knees and hip are commonly affected in adolescence and in early adulthood. gender, ethnicity or consanguinity. The present study reports the case of A.C., a 17-year-old girl. Her clinical investigation began at the age of four years, but she was only diagnosed with FOP at the age of 15 years, after being evaluated by several specialists in different centers. The patient has two siblings, but her family history did not reveal any similar cases.

Keywords - Myositis Ossificans; Ossification, Heterotopic; ACVR1 Protein; Genetics

The bones formed by FOP are a result of the progressive transformation of soft tissues in cartilage and bone. It is a process identical to that of post-fracture bone regeneration. The body can go for months without forming new bones, as if the disease were dormant; however, without prior notice and without any injury or trauma, bones can appear in unexpected places (ligaments, muscles, tendons). As a consequence, movement in the affected areas becomes difficult or impossible. Bone neoformation is designated as a flare-up. This process is generally painful, accompanied by low fever, and there is no medication that can prevent it, once it has already started. The local edema can have various causal factors:

Occurrence of flare-ups;

Restriction of movements hindering the pumping of blood inside the ossified muscles;

Compression of veins and lymphatic vessels by the new bones;

Formation of blood clot.

According to studies, the extra bones can generate cardiopulmonary complications, especially when in association with a state of flu or infection. For this

1 - Sixth-year Medical Student at the School of Medicine of Universidade Federal do Rio Grande (FURG) - Rio Grande, RS, Brazil.

2 - Professor of the Maternity and Children's Area of the School of Medicine of Universidade Federal de Rio Grande (FURG) - Rio Grande, RS, Brazil.

Study conducted in the Academic Area of Hospital Universitário Dr. Miguel Riet Corrêa Júnior, Universidade Federal de Rio Grande (FURG). Address: Rua Visconde de Paranaguá, 102, Centro 96200-190 - Rio Grande, RS.

Mailing address: Rua Dom Bosco, 1.017, bloco 4, ap. 215, bairro Hidráulica - 96211-092 - Rio Grande, RS. Email: fabyromani@yahoo.com.br

Study received for publication: 10/5/2010, accepted for publication: 11/26/2010.

The authors declare that there was no conflict of interest in conducting this work 
reason, all infections must be treated aggressively in these patients. Some patients may present right ventricular overload on account of the pulmonary hypertension that they develop, the so-called Cor Pulmonale $^{(3)}$.

The evident radiological signs of FOP are abnormal calcifications both in fingers and in toes, generating bone malformations and trabeculae. The presence of hallux valgus and other alterations of this toe is also relevant. Moreover, there have been reports of spinal fusion and the presence of osteochondromas in these patients ${ }^{(4)}$. Generally speaking, this "newly-formed skeleton" produces dental and morphological complications, mobility limitations, cardiopulmonary impairment and right ventricular overload.

\section{CASE REPORT}

A four-year-old patient referred by the orthopedist to the Medical Genetics Clinic of HCPA in 1998 for investigation. This patient was having increasing difficulty moving her limbs and neck, and presented small "bone tumors" on her back. Such clinical manifestations were associated with the rigid spine profile, and the patient remained under outpatient supervision. After seeing several specialists at different centers, she was reassessed and a full skeleton radiography was requested. Hence the diagnosis of fibrodysplasia ossificans progressiva (FOP) was confirmed six years after the first diagnostic hypothesis, and 10 years after the onset of symptoms. However, before the diagnostic conclusion, the patient underwent physiotherapy, dental and anesthetic procedures that instead of producing benefits, promoted some ossifications.

As regards family history, no similar cases or cases that could be related to the abovementioned disease were observed. The patient comes from a family of three healthy siblings (Figure 1).

The diagnosis was based on the characteristic findings evidenced in the clinical examination and in the imaging tests. In the physical examination, the patient presented malformed hallux, a classic characteristic of FOP, and the formation of "protuberances" in regions of more superficial soft tissues around the body (Figure 2), important alterations of mobility (gait, elevation and extension of the upper limbs) and of speech as well.
Some degree of breathing difficulty is also present, due mainly to the decrease of lung expandability. The radiography of chest and of upper limbs showed ossifications in regions of soft tissues (in the scapulae, shoulders and tibia), with formation of bone bridges (Figures 3, 4 and 5). The foot radiography produced findings characteristic of shortening of the halluces (Figure 6), while an important decrease of the range of mandibular motion could be visualized in the cranial computed tomography scan (Figure 7).

Besides the abovementioned findings, the patient was submitted to the collection of material for molecular analysis of DNA and is currently under outpatient clinical supervision.

\section{DISCUSSION}

It is vitally important to understand that FOP must be promptly identified, based exclusively on the clinical history, physical examination and radiographic findings, as no invasive procedures should be executed for diagnostic determination, such as excisional or non-excisional biopsies and the use of anesthetics. Moreover, dental treatments are contraindicated, since they frequently bring about ossifications in the region. Recent data revealed that $67 \%$ of patients with FOP were submitted to invasive procedures and $68 \%$ received unnecessary treatments ${ }^{(5)}$, as in the case of the patient in question. Hallux shortening was not

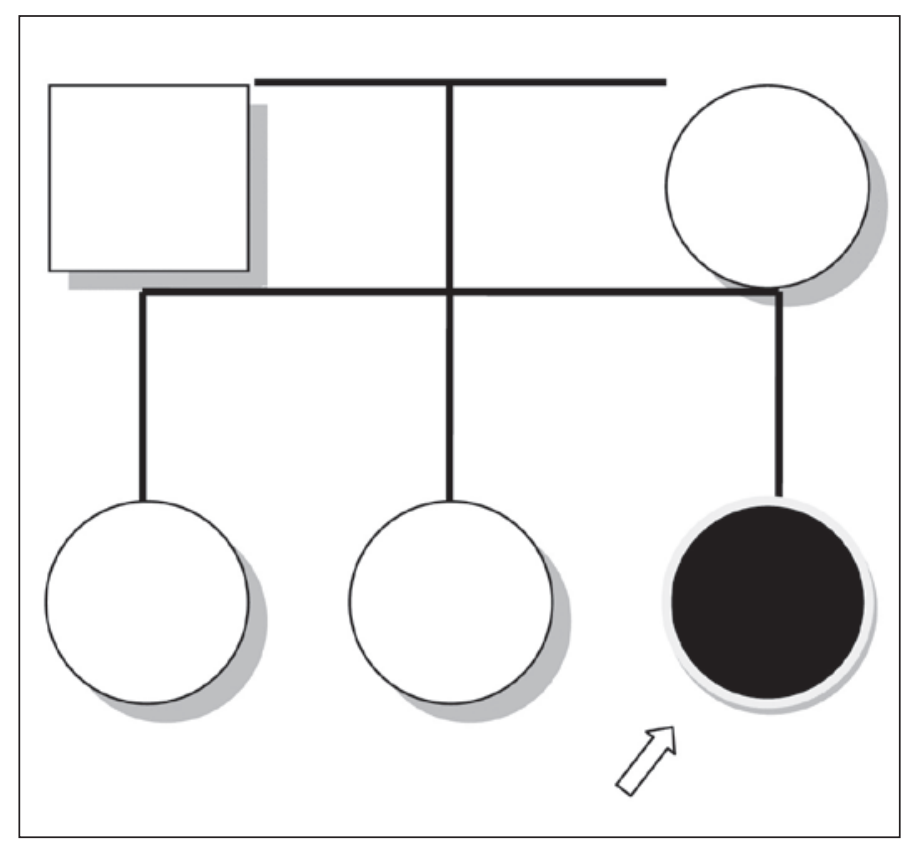

Figure 1 - A.C.'s family heredogram. 


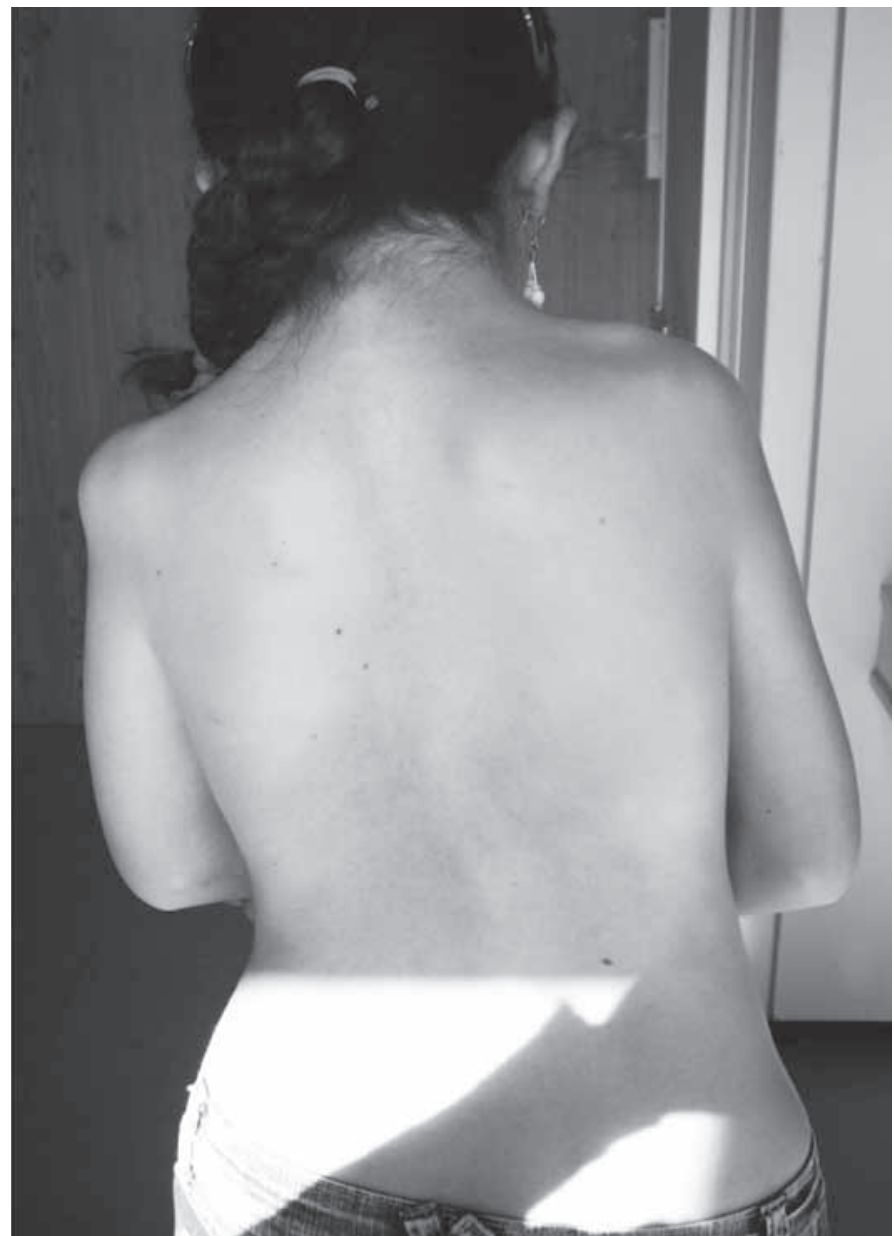

Figure 2 - Image of A.C's back, revealing scoliosis and bulging points resulting from heterotopic ossification.

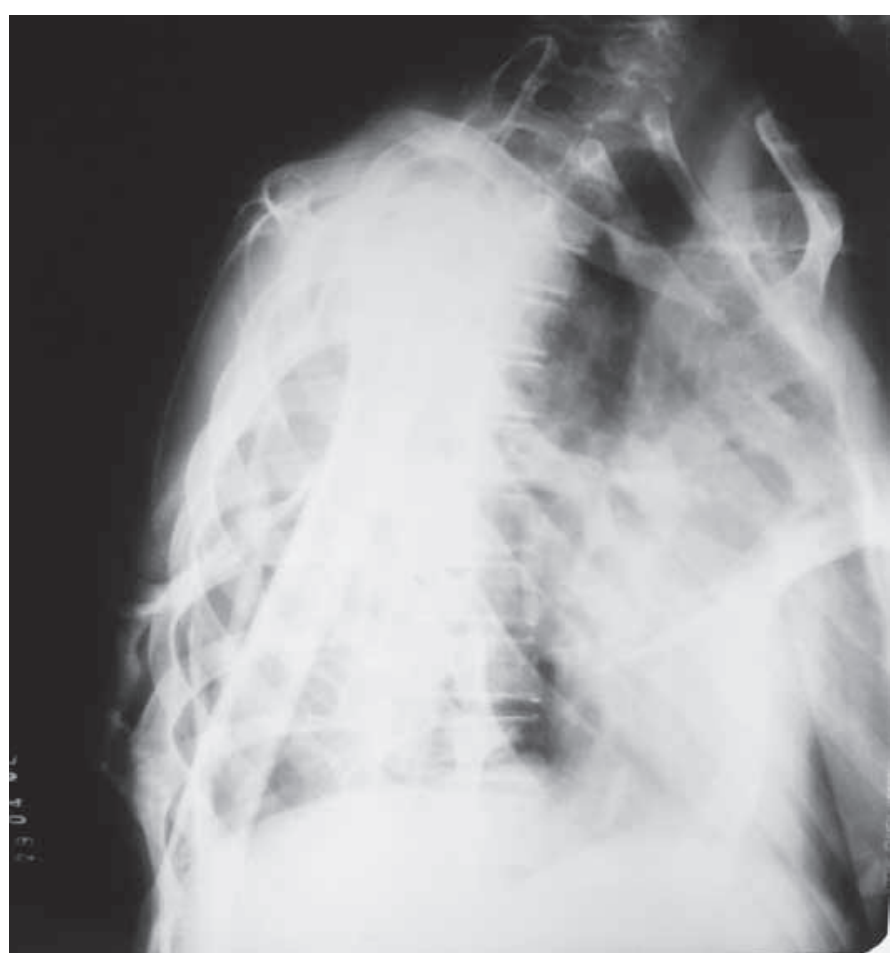

Figure 3 - Ossifications in soft parts.

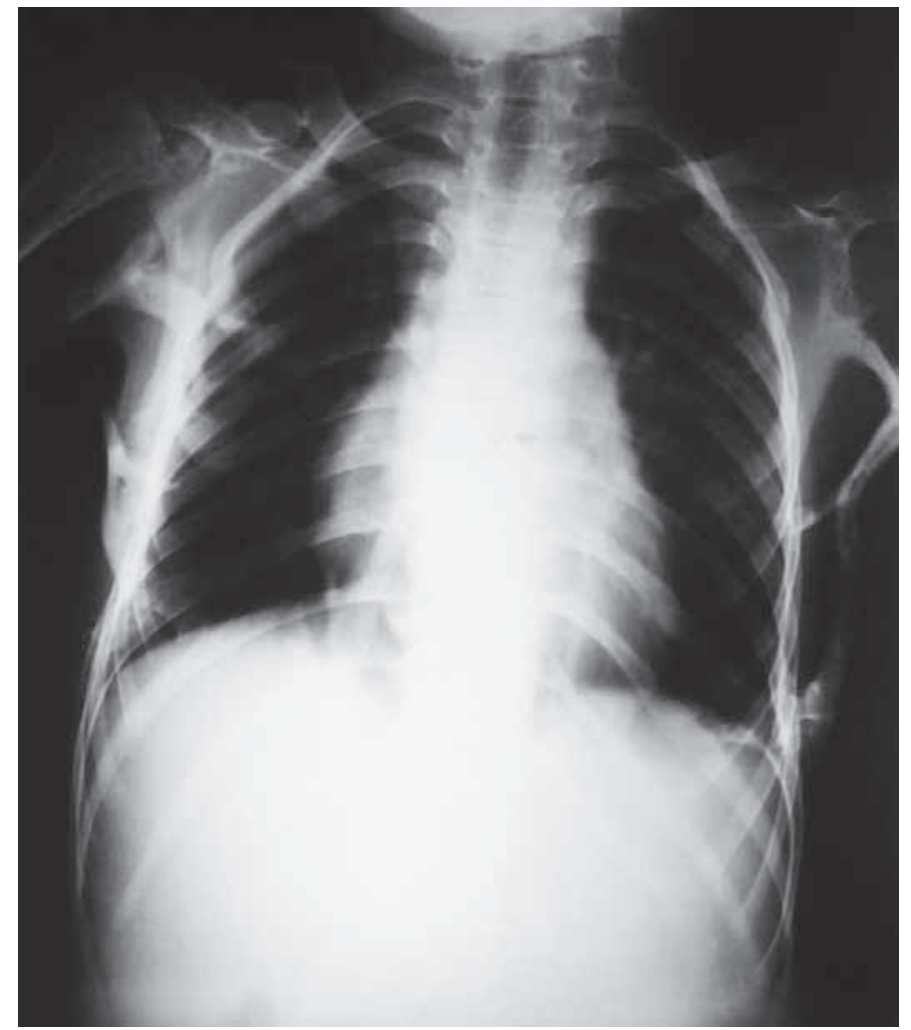

Figure 4 - Ossifications in the scapulae, shoulders and chest.

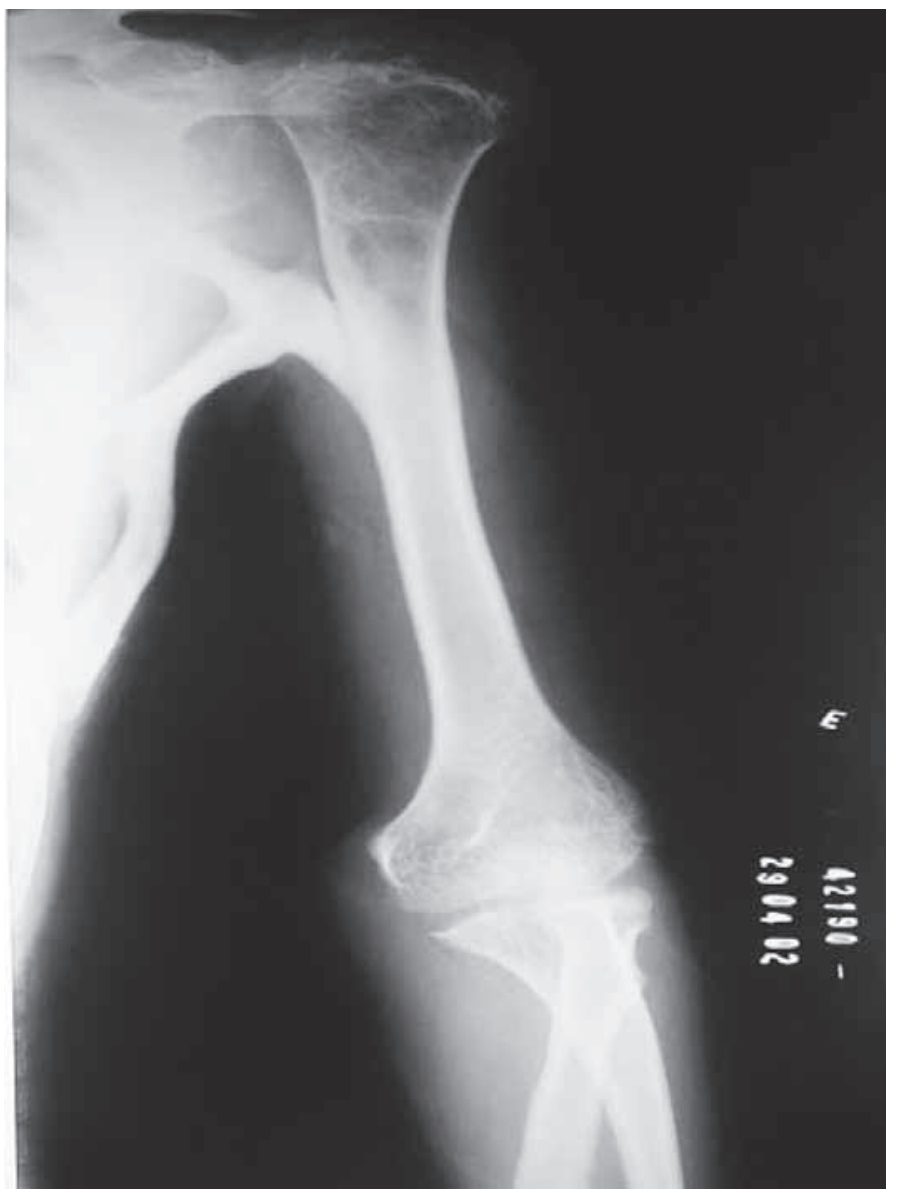

Figure 5 - Shortening of the halluces. 


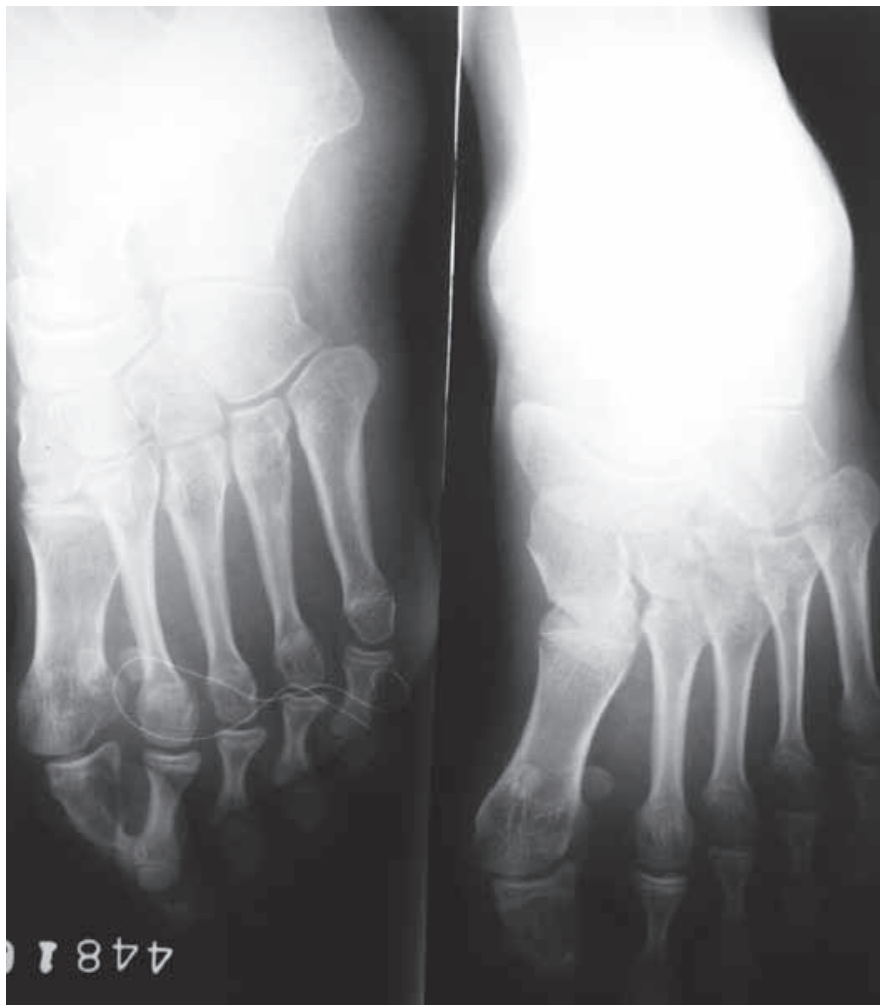

Figure 6 - Shortening of the halluces.

observed in some of the evaluations performed, while in others it was observed, but was not related to FOP. Although this type of malformation may occur in other genetic conditions or as an isolated congenital malformation, it should always refer to the diagnostic possibility of $\mathrm{FOP}^{(4)}$.

There is, as yet, no cure for this disease, and its prognosis is poor, since current treatments are still only symptomatic. However, the life expectancy of these patients is usually long, as many do not develop major comorbidities. Respiratory complications due to the formation of strips of bone that surround and immobilize the chest (restrictive syndrome), or severe malnutrition caused by difficulties in self-feeding, can limit the life expectancy of patients with FOP. At any rate, these people attain adulthood, and can reach the age of 70, when flare-ups are infrequent. However, the pace of the disease varies from patient to patient. Unfortunately, most affected individuals are confined to a wheelchair or become bedridden around the second decade of life, since the extra bones progressively create bridges between the joints, causing immobility.

Another important precaution is to maintain standards of hygiene, especially dental hygiene, as in this

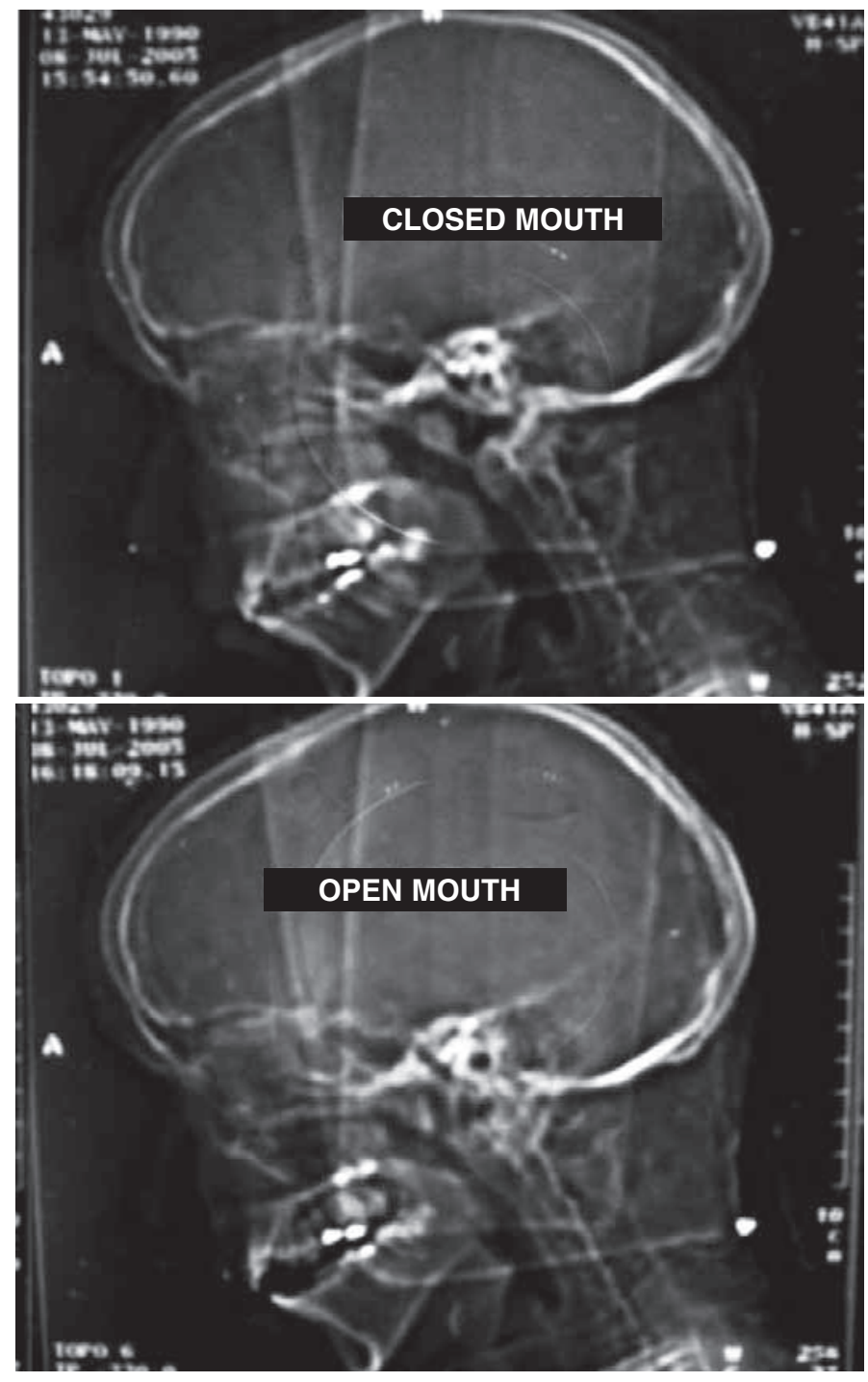

Figure 7 - Alterations in mandibular mobility seen in computed tomography.

manner we will avoid future dental problems, whose treatments are great villains for these patients, as they are potential causers of flare-ups and consequent heterotopic ossifications $^{(3)}$.

Despite all the limitations to which these individuals are subject, we should encourage socializing activities such as leisure, work and family and social conviviality, obviously taking into account the appropriate care with traumatism, thus prolonging the patient's well-being. In this context, it is essential to cite meritorious initiatives such as that of the International Fibrodysplasia Ossificans Progressiva Association (IFOPA), whose foundations are the inclusion of these patients in society and the fact that it publicizes the existence of this disorder, so that the population 
in general and the family members of those affected will understand the limitations, but more important still, the need for patients with FOP to have a less restricted, happier life ${ }^{(6)}$.

Finally, the discovery of the gene responsible for the development of the disease brought prospects of long-term treatment, and not just palliative such as those used at present ${ }^{(4)}$.

\section{ACKNOWLEDGEMENTS}

The authors are grateful to Dr. Renato Barbosa Xavier, responsible for the referral of the patient to our clinic.

\section{REFERENCES}

1. Shafritz AB, Shore EM, Gannon FH, Zasloff MA, Taub R, Muenke M, et al. Overexpression of an osteogenic morphogen in fibrodysplasia ossificans progressiva. N Engl J Med. 1996;335(8):555-61.

2. Gonçalves AL, Masruhsa MR, Campos CC, Delai PLR; Vilanova LCP. Fibrodysplasia ossificans progressiva. Arq Neuropsiquiatr. 2005; 63(4):1090-3.

3. Wagman RB, Kantanie SL, Kaplan FS. O q é FOP? Um guia para famílias. 2003.
4. Kaplan FS, Xu M, Glaser DL, Collins F, Connor M, Kitterman J, et al. Early diagnosis of fibrodysplasia ossificans progressiva. Pediatrics. 2008;121(5):e1295-300.

5. Kitterman JA, Kantanie S, Rocke DM, Kaplan FS. latrogenic harm caused by diagnostic errors in fibrodysplasia ossificans progressiva. Pediatrics. 2005;116(5):e654-61.

6. International Fibrodysplasia Ossificans Progressiva Association (IFOPA). FOP Conection; 2004. 